\title{
Regulating reserve with large penetration of renewable energy using midterm dynamic simulation
}

\author{
Chaoyang JING ( $ه)$, Baiqing LI
}

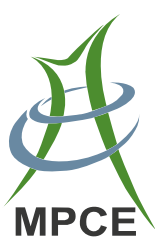

\begin{abstract}
A novel renewable energy intermittency model and a new midterm dynamic simulation tool in power systems are developed for examining dynamic behavior along the load curve for different combinations of the system operation reserves and renewable portfolio standard (RPS) rates. The system's import limits are considered. It is concluded that ignoring intermittency and governor effects is an inadequate method to assess intermittency impact. The intermittency midterm dynamic impact must be studied. For the studied system, the instability is expected to be about $25 \%$ RPS with current reserves. Besides, the most vulnerable peak hour to instability is the afternoon peak hour when solar begins to drop off. This article stimulates further dynamic intermittency studies on the issues caused by renewable intermittency. The studies on the issues caused by renewable intermittency have not been revealed because of inadequate/ incomprehensive study methodologies so that effective, mitigative solutions can be developed to guarantee the reliability of power grid when incorporating higher RPS if high operation reserves are impractical.
\end{abstract}

Keywords Renewable energy intermittency, Midterm dynamic simulation, Power systems, Dynamic stability, Renewable portfolio standard (RPS)

\section{Introduction}

Growing environmental concerns and attempts to reduce dependency on fossil fuel energy resources are bringing

Received: 31 July 2012/ Accepted: 2 November 2012/Published online: 11 July 2013

(C) The Author(s) 2013. This article is published with open access at Springerlink.com

C. JING, eMIT, LLC, Pasadena, CA 91107, USA

$(\bowtie)$ e-mail: c.jing@myemit.com

B. LI, China Electric Power Research Institute, Beijing, China renewable energy resources to the generation portfolio of electric power utilities. Among the various renewable resources, wind power and solar power are assumed to have the most favorable technical and economical prospects. The effective integration of wind in power system operations requires a comprehensive approach to data management and decision making. The variability and uncertainty of wind power will require the increased flexibility from other power system resources, and the adaptation of business processes and control systems to manage these resources. Efficient use of grid resources to maintain reliability and minimize costs argues in favor of both tighter integration of systems and, at the same time, an open infrastructure can take advantage of evolving tools and grid devices.

California is aggressively bringing renewable generation online to meet its renewables portfolio standard (RPS), one of the most ambitious renewable standards in USA.

California's RPS requires retail sellers (investor-owned utilities (IOUs), electric service providers (ESPs), and community choice aggregators (CCAs)) regulated by the California Public Utilities Commission (CPUC) to procure $33 \%$ of its retail sales per year from eligible renewable sources by 2020 . The RPS also requires retail sellers to achieve intermediate RPS targets of $20 \%$ from 2011 to 2013 and of $25 \%$ from 2014 to 2016. The CPUC and the California Energy Commission (CEC) are jointly responsible for implementing California's $33 \%$ RPS program [1].

In order to meet its mandated renewable generation goals, the company studied is bringing large amounts of wind generation from remote desert areas into the bulk system. In addition, it is planned to connect significant amounts of solar PV energy resources in its eastern service territory. The increase in the penetration of renewable resources, with effectively low inertia facilities, will cause a change in the system dynamics. In order to better understand these changes on the system dynamic behavior, 
adequate studies need to be conducted to assess the possible negative intermittency impact and solutions. Unlike the load, a renewable energy cannot accurately forecast far in advance, and renewable power can vary over its full range of the capacity. Though the impact on system reliability is similar to that of unscheduled outages, it occurs far more frequently, and the operating costs associated with reserve dispatch are much more significant. Power system operators secure different amounts and types of operating reserves to compensate for these characteristics to reliably serve load and maintain the system frequency.

The output of renewable generation varies with the energy source. For example, solar panels do not produce electricity when the sun does not shine, and wind turbines do not spin when the wind does not blow. However, it is not just an on-or-off proposition. The output from solar and wind can vary over relatively short periods depending on cloud cover and shifting wind speeds. This intermittency produces challenges to managing demand on specific parts of the grid and ensuring adequate capacity.

The impact of renewable energy intermittency on the system operation needs to be urgently studied when the load varies from minute to minute. Most of the renewable energy studies published so far focus on power flow balancing generation, load and losses, without taking the dynamic behavior of power system into consideration [1-4]. Some approaches for dealing with intermittency use probabilistic method to smooth out the variability [1, 3-11], which cannot guarantee a reliable grid operation all the time. It is challenging to study the renewable intermittency impact without commercial tools that can be used to model and study the intermittency. Some severe issues with integration of renewable energy can only be revealed by studying the dynamic intermittency behavior of the renewable energy, especially when the load varies from minute to minute.

This article develops a new renewable energy intermittency model and a novel power system simulation tool, and examines the dynamic behavior along the load curve for different combinations of the system operation reserves and RPS rates. The system stability is classified based on the midterm dynamic simulation. It is found that ignoring intermittency and governor effects is an inadequate method to assess intermittency impact. Therefore, the intermittency midterm dynamic impact must be studied. For the studied system, the instability is expected to be around $25 \%$ RPS with the current reserves. It is also identified that most vulnerable peak hour to instability is the afternoon peak hour when solar power begins to drop off. This article tries to stimulate further dynamic intermittency studies on the issues caused by renewable intermittency, which have not been revealed because of inadequate/incomprehensive study methodologies. Based on the study, effective mitigative solutions can be developed to guarantee the reliability of power grid when incorporating higher RPS if high regulating reserves are impractical.

\section{Renewable energy model and new midterm dynamic simulation tool}

The variability of wind and solar is measured over different time-scales. Beginning on the time-scale of minutes, Fig. 1 shows the variability in wind and solar PV generation on a minute-by-minute basis over the full day. The implication for system operations are that, unless the variability is smoothed by the variable energy resource itself, other resources have to increase or decrease their generation on similar time frames (seconds, minutes, and hours) to compensate for the supply variability.

In any power system, a frequency is controlled by balancing the power generation against the load demand on a second-by-second basis. There is a need for continuous adjustment of generator output as the load demand varies. In the meantime, the system can respond to larger mismatches in generation, renewable intermittency, and load changes [12-17].

The variable, nondispatchable nature of wind and solar has a significant impact on the utility reserve requirement. The effect analysis of the renewable resource intermittency provides a meaningful and concrete method for characterizing the variability of renewable energy resources.

Whenever there is load/generation imbalance, synchronous generators in a system respond in three stages to bring the system back to normal operation. The initial stage is characterized by the release or absorption of kinetic energy of the rotating mass-this is a physical and inherent characteristic of synchronous generators. For example, if there is a sudden increase in load or in renewable generation due to intermittency, the electrical torque increases to

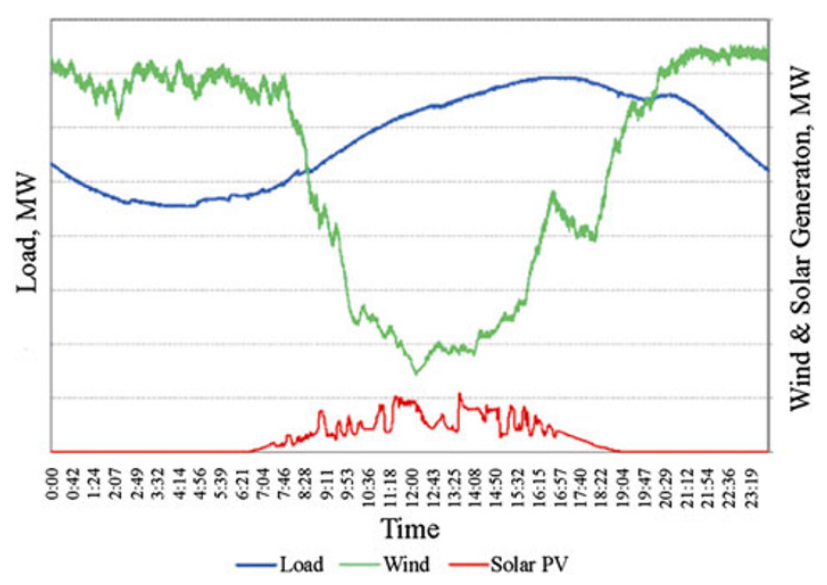

Fig. 1 Wind and solar generation for 1 day 
supply load increase, while the mechanical torque of the turbine initially remains constant. Hence, the acceleration becomes negative. The turbine-generator decelerates, and the rotor speed drops as kinetic energy is released to supply the load change. This response is called "inertial response." As the frequency deviation exceeds certain limit, the turbinegovernor control will be activated to change the power input to the prime mover. The rotor acceleration eventually becomes zero, and the frequency reaches a new steady state. This is called "primary frequency control." After primary frequency support, there still exists steady-state frequency error. To remove the error, the governor set points are changed, and the frequency is brought back to nominal value, which is called "secondary frequency control." These three phenomena take place in succession in any system to restore the normal operating equilibrium.

The characteristic of the wind generation is that it could ramp up from zero all the way to its maximum in half an hour, and it could also ramp down from its maximum to zero in half an hour. The questions to answer the renewable intermittency impact are as follows:

(1) Is the operation reserve large enough when the load increases and, at the same time, wind generations ramp down to zero in half an hour?

(2) Is the system's response fast enough when the load decreases and, at the same time, wind generations ramp up to its maximum from zero in half an hour?

Note that there is no need to study the scenario that wind generation increases when the load increases. Similarly, there is no need to study the scenario that wind generation decreases when the load decreases as the key thing is to examine if the system has enough reserves and if the governor response is fast enough to compensate the renewable intermittency and load variation.

Since RPS in California will be $33 \%$ in 2020, the scenarios will be studied in 2020. The load curve for Sept 27, 2020, based on load forecast, is shown in Fig. 2. It is assumed that Sept 27, 2020 will be the peak load day for the year of 2020 .

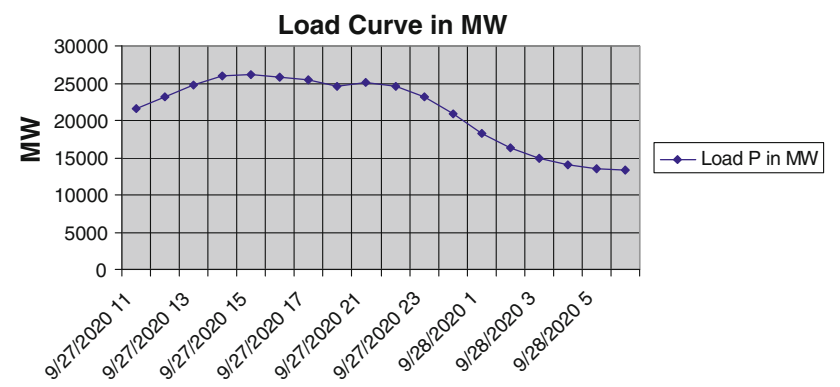

Fig. 2 Load curve for Sept 27, 2020
To answer the above question, the renewable energy is modeled as follows:

(1) When the load increases before hour 15, wind generation decreases from its maximum (2,061 MW) to zero in $30 \mathrm{~min}$.

(2) When the load decreases after hour 15, wind generation increases from zero to its maximum $(2,061 \mathrm{MW})$ in $30 \mathrm{~min}$.

In this article, the solar generation intermittency is not considered to enable a simplified approach. One of the justifications is that, in Southern California, the location of the company, there are about 300 sunny days in a year. However, the solar generation varies along the load curve. It starts from 6 a.m., reaches its maximum at noon, and goes down to zero around 7 p.m. The solar generation model is similar to what is shown in Fig. 1.

Figure 3 illustrates the process of intermittency dynamics study, in which the load peaks around 15 p.m., solar power output peaks around noon, and the wind generation variability is modeled.

As Positive Sequence Load Flow (PSLF) and Power System Simulation Engineering (PSS/E) (which are transient tools that examine a $10-20 \mathrm{~s}$ time period) cannot simulate midterm intermittency, which would require that load and generation changes occur with simulation time, typically held constant, a novel time domain simulation program was developed.

$$
\begin{aligned}
\mathrm{d} \boldsymbol{x} / \mathrm{d} \boldsymbol{t} & =\boldsymbol{f}(\boldsymbol{x}, \boldsymbol{V}) \\
\boldsymbol{I}(\boldsymbol{x}, \boldsymbol{V}) & =\boldsymbol{Y} \boldsymbol{V},
\end{aligned}
$$

where $\boldsymbol{x}$ is the state vector; $\boldsymbol{f}$ is the nonlinear vector function; $\boldsymbol{V}$ is the vector of complex nodal voltages; $\boldsymbol{Y}$ is the nodal admittance matrix; and $\boldsymbol{I}$ is the vector of injected nodal currents.

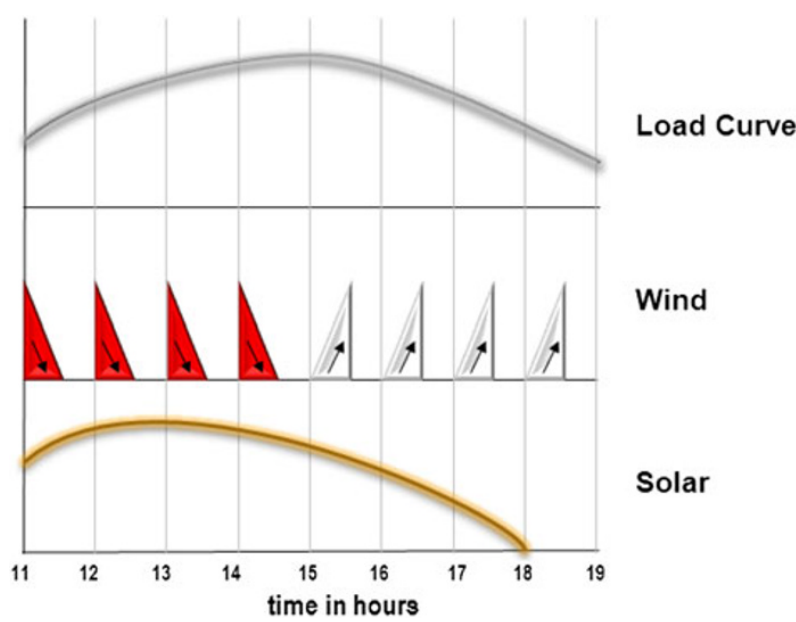

Fig. 3 Illustration of intermittency dynamics study 
The differential equations represent the dynamic behavior of the system elements (synchronous machines and their controllers, etc.) and the algebraic equations represent the network equations and the connection of the external elements to the network. The generators are modeled in detailed model with excitation, PSS control, and governor/Automatic Generation Control (AGC) controls. The load is modeled in nonlinear Impedance, Current, Power (ZIP) model.

A mathematical intermittency model is developed using differential equations that describe the midterm dynamic space and, which uses trapezoidal integration methods to determine the stability/instability resulting from the intermittency changes arising from renewable resources and the natural time varying attributes of system load.

The solution scheme can be classified according to the numerical method applied to the differential equations (implicit or explicit) and the strategy to solve the differential and algebraic sets of equations (alternating or simultaneous).

\section{Simulation results using renewable energy model and new midterm dynamic simulation tool}

The impact of the high penetration of the renewable resources on the studied system can be described as follows. Significant amount of wind resources are added north-east of the system. The solar resources are primarily added east of the system.
The load, wind generation, solar generation, and generations with governor controls for different time intervals are listed in Table 1.

3.1 Study results for $30 \%$ rps with $25 \%$ reserve along the load curve

Table 2 shows the ramp rate results for $30 \%$ RPS with $25 \%$ reserve along the load curve. Table 2 is obtained by running midterm dynamic simulation for $30 \mathrm{~min}$ for 18 scenarios defined in Table 1.

During each dynamic simulation

(1) The load is modeled using Fig. 2 for each corresponding time interval.

(2) The solar generation is modeled using Table 1 for each corresponding time interval and follows the change shown in Fig. 3.

(3) The wind generator is modeled as follows.

When the load increases before hour 15, wind generation decreases from its maximum $(2,061 \mathrm{MW})$ to zero in 30 min, as shown in Fig. 4.

When the load decreases after hour 15 , wind generation increases from zero to its maximum $(2,061 \mathrm{MW})$ in 30 min, as shown in Fig. 5.

Table 2 shows that hour 15 requires the largest ramp rate, which is $81 \mathrm{MW} / \mathrm{min}$. Note that hour 15 is the hour at

Table 1 Wind, solar, and conventional generations and loads for different time intervals

\begin{tabular}{|c|c|c|c|c|c|c|c|c|}
\hline Time & $\begin{array}{l}\text { Load P } \\
\text { in MW }\end{array}$ & $\begin{array}{l}\text { Load Q } \\
\text { in MVAR }\end{array}$ & $\begin{array}{l}\text { Wind Gen } \\
\mathrm{P} \text { in MW }\end{array}$ & $\begin{array}{l}\text { Win Gen Q } \\
\text { in MVAR }\end{array}$ & $\begin{array}{l}\text { Solar Gen } \\
\mathrm{P} \text { in MW }\end{array}$ & $\begin{array}{l}\text { Solar Gen } \\
\text { Q in MVAR }\end{array}$ & $\begin{array}{l}\text { Conventional } \\
\text { Gen P in MW }\end{array}$ & $\begin{array}{l}\text { Conventional } \\
\text { Gen Q } \\
\text { in MVAR }\end{array}$ \\
\hline 9/27/2020 11:00 & $21,620.09$ & $1,081.005$ & 2,061 & 206.1 & 3,646 & 364.6 & $8,851.094$ & 510.305 \\
\hline 9/27/2020 12:00 & $23,213.84$ & $1,160.692$ & 2,061 & 206.1 & 4,376 & 437.6 & $9,714.842$ & 516.992 \\
\hline 9/27/2020 13:00 & $24,819.07$ & $1,240.954$ & 2,061 & 206.1 & 3,646 & 364.6 & $12,050.072$ & 670.254 \\
\hline 9/27/2020 14:00 & $26,035.05$ & $1,301.753$ & 2,061 & 206.1 & 2,916 & 291.6 & $13,996.053$ & 804.053 \\
\hline 9/27/2020 15:00 & $26,149.88$ & $1,307.494$ & 2,061 & 206.1 & 2,186 & 218.6 & $14,840.875$ & 882.794 \\
\hline 9/27/2020 16:00 & $25,759.48$ & $1,287.974$ & 2,061 & 206.1 & 1,456 & 145.6 & $17,241.477$ & $1,142.374$ \\
\hline 9/27/2020 17:00 & $25,443.71$ & $1,272.186$ & 2,061 & 206.1 & 726 & 72.6 & $17,655.713$ & $1,199.586$ \\
\hline 9/27/2020 18:00 & $24,568.76$ & $1,228.438$ & 2,061 & 206.1 & 0 & 0 & $17,506.758$ & $1,228.438$ \\
\hline 9/27/2020 19:00 & $25,005.09$ & $1,250.254$ & 2,061 & 206.1 & 0 & 0 & $17,943.086$ & $1,250.254$ \\
\hline 9/27/2020 20:00 & $24,494.12$ & $1,224.706$ & 2,061 & 206.1 & 0 & 0 & $17,432.123$ & $1,224.706$ \\
\hline 9/27/2020 21:00 & $23,104.76$ & $1,155.238$ & 2,061 & 206.1 & 0 & 0 & $16,042.76$ & $1,155.238$ \\
\hline 9/28/2020 22:00 & $20,876.04$ & $1,043.802$ & 2,061 & 206.1 & 0 & 0 & $13,814.039$ & $1,043.802$ \\
\hline 9/28/2020 23:00 & $18,289.07$ & 914.453 & 2,061 & 206.1 & 0 & 0 & $11,227.068$ & 914.453 \\
\hline 9/28/2020 0:00 & $16,265.88$ & 813.294 & 2,061 & 206.1 & 0 & 0 & $9,203.38$ & 813.294 \\
\hline 9/28/2020 1:00 & $14,935.08$ & 746.754 & 2,061 & 206.1 & 0 & 0 & $7,873.077$ & 746.754 \\
\hline 9/28/2020 2:00 & $14,052.09$ & 702.604 & 2,061 & 206.1 & 0 & 0 & $6,990.085$ & 702.604 \\
\hline 9/28/2020 3:00 & $13,469.93$ & 673.497 & 2,061 & 206.1 & 0 & 0 & $6,407.931$ & 673.497 \\
\hline 9/28/2020 4:00 & $13,312.62$ & 665.631 & 2,061 & 206.1 & 0 & 0 & $6,250.622$ & 665.631 \\
\hline
\end{tabular}


Table 2 Governor ramp rate for $30 \%$ RPS along the load curve

\begin{tabular}{lllll}
\hline ID & Time & $\begin{array}{l}\text { Ramp rate } \\
\text { (MW/Min) }\end{array}$ & $\begin{array}{l}\text { Max. frequency } \\
\text { variation (Hz) }\end{array}$ & Remarks \\
\hline 1 & 11 & 54 & -0.02 & \\
2 & 12 & 80 & -0.03 & Load peak \\
3 & 13 & 80 & -0.03 & \\
4 & 14 & 79.7 & -0.03 & \\
5 & 15 & 81 & -0.03 & \\
6 & 16 & -57 & 0.002 & \\
7 & 17 & -56 & 0.019 & \\
3 & 18 & -67 & 0.023 & \\
9 & 19 & -67 & 0.023 & \\
10 & 20 & -67 & 0.023 & \\
11 & 21 & -67 & 0.023 & \\
12 & 22 & -67 & 0.023 & \\
13 & 23 & -67 & 0.023 & \\
14 & 0 Next & -66 & 0.023 & \\
& day & & 0.023 & \\
15 & 1 & -67 & 0.023 & \\
16 & 2 & -67 & 0.0023 & \\
17 & 3 & -67 & & \\
\hline & & & & \\
\hline
\end{tabular}

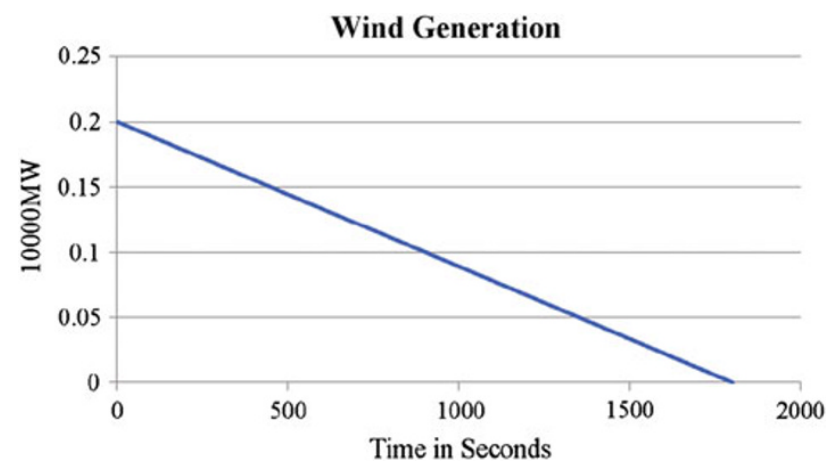

Fig. 4 Wind generation intermittency model when load increases

which load reaches its peak during that day, and when the load decreases, the ramp rate is almost the same.

The result shown in Table 2 is benchmarked with what was obtained from the Market Simulator used by the company's market operation department.

Figure 6 shows the total real power output of generators with governor control for hour 14 .

Figure 7 shows the frequency response for hour 14. As the load increases and the wind generation decreases, the frequency decreases.

Figure 8 shows the real power of wind generator for hour 14.

Figures 9 and 10 show the output for hour 1 a.m. of the next morning. As the load decreases, the frequency increases

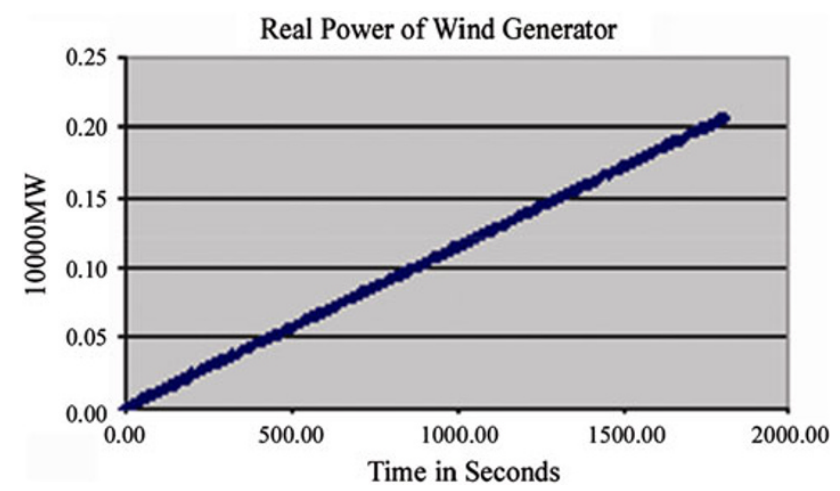

Fig. 5 Wind generation intermittency model when load decreases

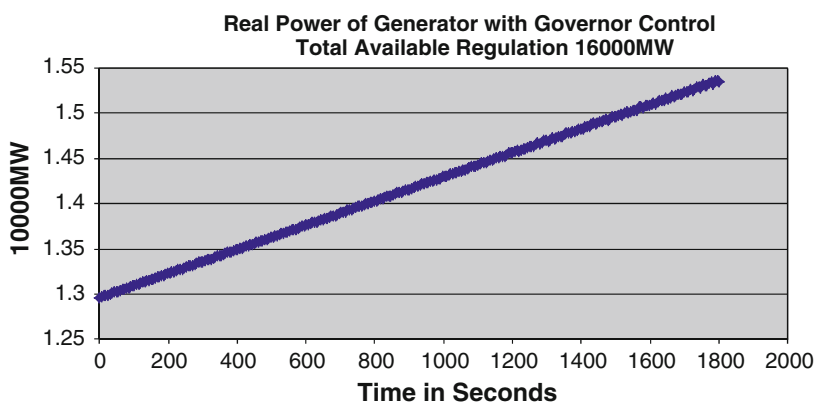

Fig. 6 Total real power of generators with governor control for hour 14

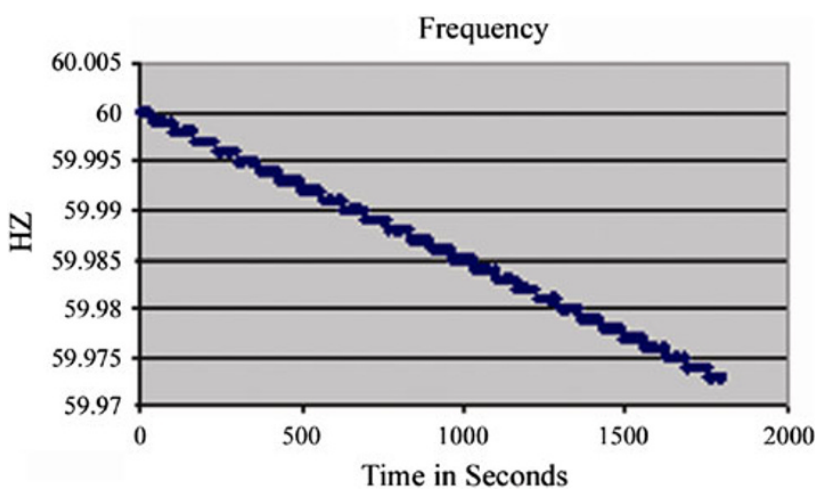

Fig. 7 Frequency response for hour 14

and the real power of generator with the governor decreases. It is assumed that the wind generation increases from zero to its maximum in $30 \mathrm{~min}$ as it is the worst scenario for the study. It is found that the governor response is not fast enough to reduce the generation, which is why there is chattering in the generator output, as shown in Fig. 9.

\subsection{Study results for different rps and different reserves for hour 15}

It is identified that hour 15 is the most critical one in system operation, and this section summarizes the detailed 


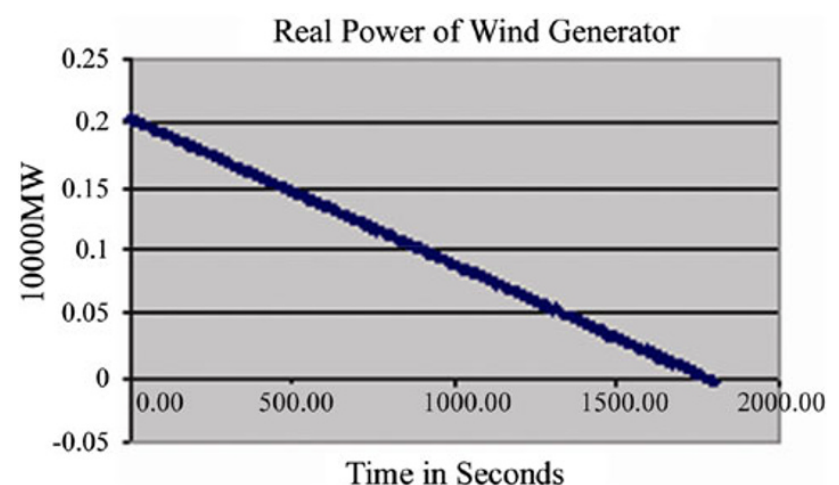

Fig. 8 Real power of wind generator for hour 14

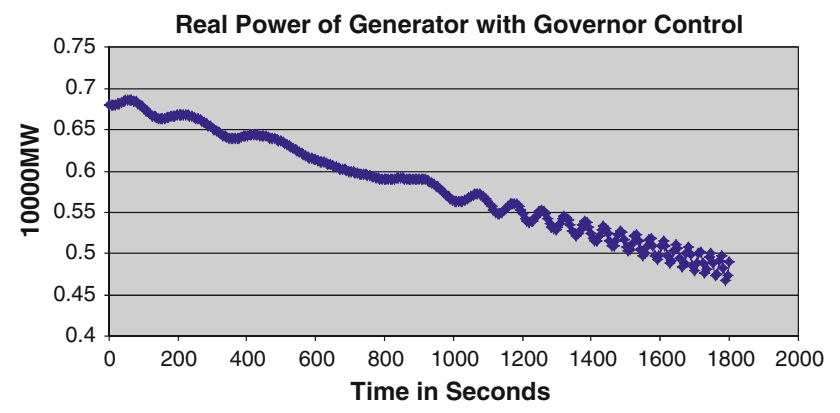

Fig. 9 Real power of generation with governor control

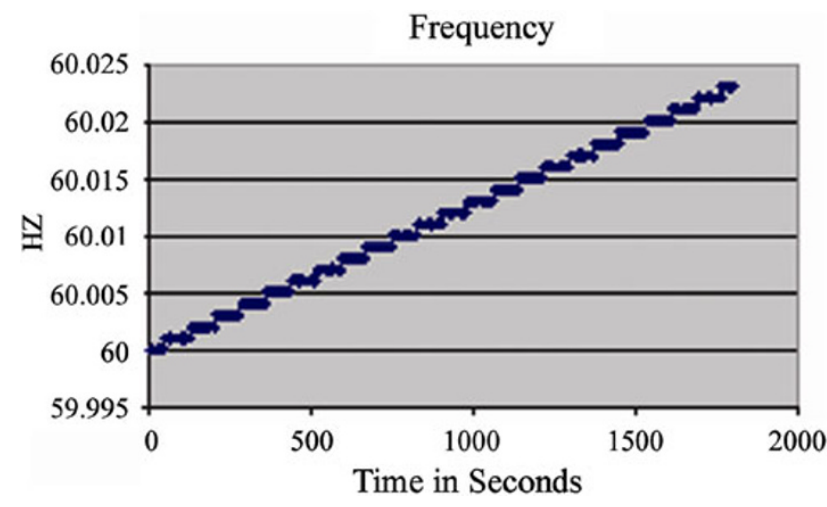

Fig. 10 Frequency for 1 a.m. of next morning study for different RPSs for hour 15. In the simulation, wind generation decreases from its maximum to zero in $30 \mathrm{~min}$. The solar generation is modeled, as shown in Fig. 1, for the time period between hour 15 and hour 15:30. The load is modeled using the load curve shown in Fig. 2 for the time period between hour 15 and hour 15:30.

In Table 3, the stable system is classified if the frequency recovers back to $58.0 \mathrm{~Hz}$, and the unstable system is classified if the frequency cannot recover back to $58.0 \mathrm{~Hz}$.

It is concluded from Table 3 that the higher the RPS, the higher the required reserve, and thus, the system can operate within the stability region when the renewable energy intermittence occurs for the worst scenarios.

Note that the system will become unstable when RPS reaches $25 \%$ with $15 \%$ reserve, which is the current reserve level. Currently, RPS rate is $20 \%$, and the reserve is $15 \%$ at the company. The key findings of the study are helping the company to come up with effective mitigative solutions to guarantee the reliability of the power grid when incorporating higher RPS.

\subsection{Study results for $33 \%$ RPS for hour 15}

Table 3 shows that $33 \%$ RPS with $25 \%$ Reserve will make the system unstable. Figures 11, 12, 13 show the dynamic responses for $30 \mathrm{~min}$ starting from hour 15 . It is concluded that the system is unstable as the frequency drops below $55 \mathrm{~Hz}$ and never be able to recover. Note that Fig. 13 is numerical simulation results when the system collapses as the remedial action system is not enabled in the simulation. The oscillation is because the system becomes unstable, and the numerical simulation continues.

\subsection{Mitigation for $33 \%$ RPS for hour 15}

Subsection 3.3 shows that the system is unstable for $33 \%$ RPS. One of mitigations is to import more generations from external resources to stabilize the power system when the renewable energy penetration is very high.

Figure 14 shows the real power of generator with governor, and Fig. 15 shows the frequency response when

Table 3 Study results for different RPSs for hour 15

\begin{tabular}{lrrrrr}
\hline & \multicolumn{1}{c}{$15 \%$ Reserve } & 20\% Reserve & $25 \%$ Reserve & $30 \%$ Reserve & $35 \%$ Reserve \\
\hline $20 \%$ RPS & Stable (2,078 MW) & Stable (2,770 MW) & Stable (3,463 MW) & Stable (4,156 MW) & Stable (4,849 MW) \\
$25 \%$ RPS & Unstable (1,882 MW) & Stable (2,509 MW) & Stable (3,137 MW) & Stable (3,764 MW) & Stable (4,391 MW) \\
$30 \%$ RPS & Unstable (1,686 MW) & Unstable (2,248 MW) & Stable (2,810 MW) & Stable (3,372 MW) & Stable (3,934 MW) \\
$33 \%$ RPS & Unstable (1,568 MW) & Unstable (2,091 MW) & Unstable (2,613 MW) & Unstable (3,136 MW) & Stable (3,659 MW) \\
$35 \%$ RPS & Stable (1,489 MW) & Unstable (1,986 MW) & Unstable (2,483 MW) & Unstable (2,979 MW) & Unstable (3,476 MW) \\
\hline
\end{tabular}




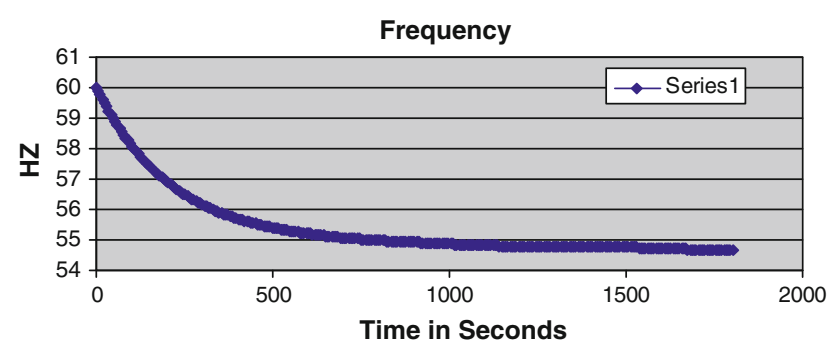

Fig. 11 Frequency for $33 \%$ RPS for hour 15

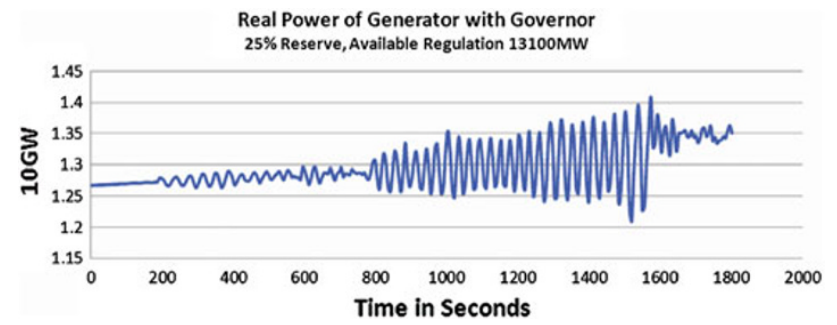

Fig. 12 Real power of generator with governor for $33 \%$ RPS for hour 15

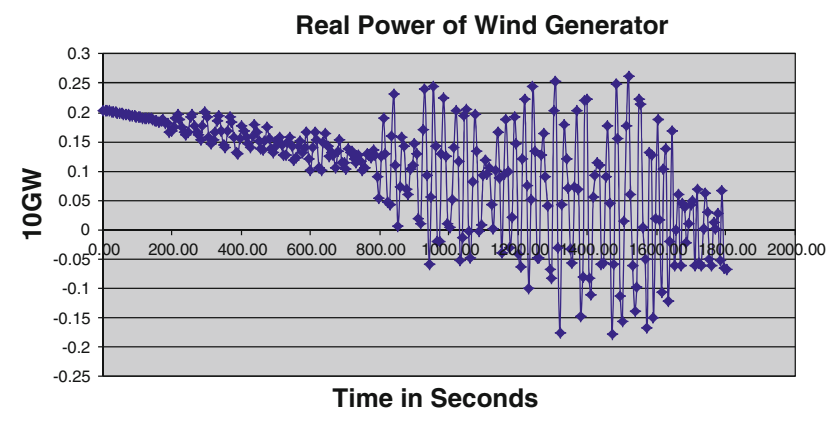

Fig. 13 Real power of wind generator for hour 15

adding external generation resources, indicating that the import helps in stabilizing the power grid.

\section{Conclusions}

This article developed a novel renewable energy intermittency model, a new power system simulation tool, and examined the dynamic behavior along the load curve for different combinations of the system operation reserves and RPS rates. The key findings of this study can help the company better prepare for the renewable integration and adopt effective mitigation. Besides, the study reveals some severe issues that can only be identified by studying the intermittency dynamics.

The conclusions and the suggestions for future study are as follows:

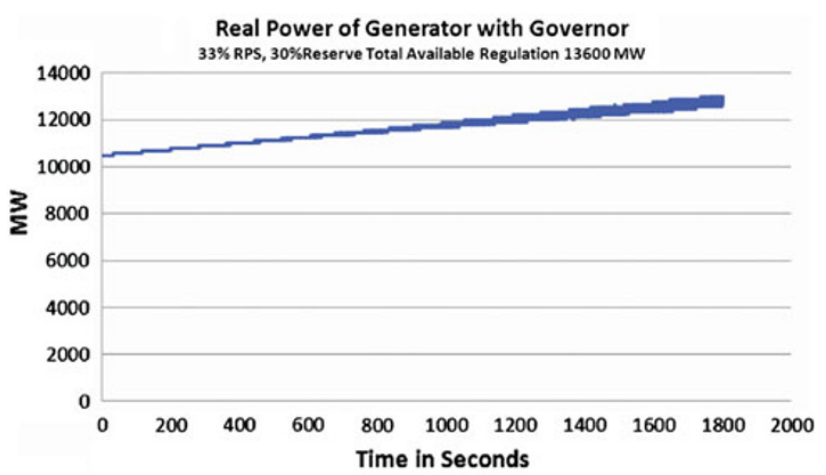

Fig. 14 Real power of generator with governor when adding external generation resources

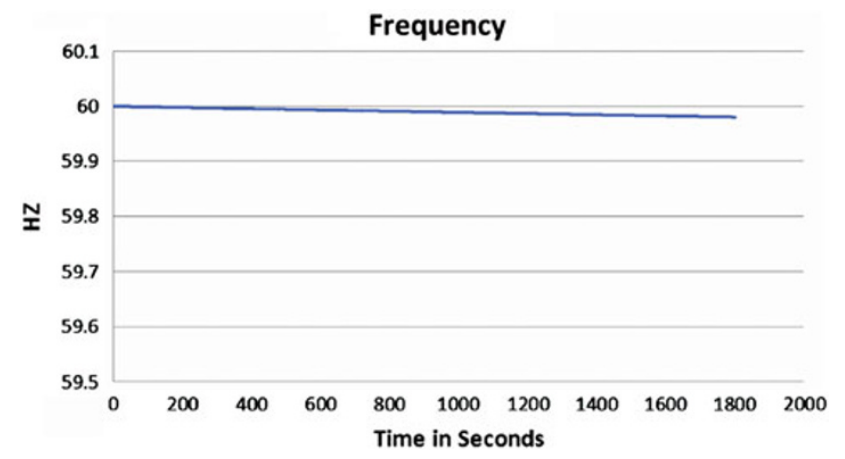

Fig. 15 Frequency after adding external generation resource

(1) Ignoring intermittency and governor effects is an inadequate method to assess intermittency impact.

(2) The intermittency midterm dynamic impact is studied to gain better understanding of the high renewable penetration.

(3) The higher the RPS, the higher the required reserve.

(4) The company expects instability of around $25 \%$ RPS with current reserves.

(5) Dynamic stability depends on (1) RPS rate; and (2) operation reserves, governor response speed, quick start resources, and resources under AGC control; (3) import limit.

(6) Most vulnerable peak hour to instability is the afternoon peak hour when solar begins to drop off.

(7) Investigate energy storage to mitigate problems.

(8) External generation resources will help in stabilizing the system with $33 \%$ renewable energy integration.

Open Access This article is distributed under the terms of the Creative Commons Attribution License which permits any use, distribution, and reproduction in any medium, provided the original author(s) and the source are credited. 


\section{References}

[1] ISO (2010) ISO study of operational requirements and market impacts at 33\% RPS. CPUC workshop on CAISO and PG\&E renewable integration model methodologies

[2] EnerNex Corporation (2006) Minnesota wind integration study. Final report, vol 1. EnerNex Corporation, Knoxville

[3] California ISO (2010) Integration of renewable resources: operational requirements and generation fleet capability at $20 \%$ RPS

[4] Bonneville Power Administration (2007) Large wind integration impacts on operations/system reliability. Bonneville Power Administration, Portland

[5] Ela E, Kirby B, Lannoye E et al (2010) Evolution of operating reserve determination in wind power integration studies. In: Proceedings of the 2010 IEEE Power and Energy Society general meeting, Minneapolis

[6] Philbrick CR (2010) Wind integration and the evolution of power system control. In: Proceedings of the 2010 IEEE Power and Energy Society general meeting, Minneapolis, 25-29 July 2010

[7] Teleke S, Baran ME, Bhattacharya S et al (2010) Validation of battery energy storage control for wind farm dispatching. In: Proceedings of the 2010 IEEE Power and Energy Society general meeting, Minneapolis, 25-29 July 2010

[8] Usaola J, Ledesma P (2001) Dynamic incidence of wind turbines in networks with high wind penetration. In: Proceedings of the 2001 IEEE Power Engineering Society summer meeting, vol 2, Vancouver, 15-19 July 2001, pp 755-760

[9] Vittal V, Mccalley JD, Ajjarapu V et al (2010) Impact of increased DFIG wind penetration on power systems and markets. Final project report, PSERC 09-10, Power Systems Engineering Research Center, Arizona State University, Tempe

[10] Slootweg JG, de Haan SWH, Polinder H et al (2001) Modeling wind turbines in power system dynamics simulations. In: Proceedings of the 2001 IEEE Power Engineering Society summer meeting, vol 1, Vancouver, Canada, 15-19 July 2001, pp 22-26

[11] Kehler J, Hu M, Mcmullen M et al (2010) ISO perspective and experience with integrating wind power forecasts into operations. In: Proceedings of the 2010 IEEE Power and Energy
Society general meeting, Minneapolis, 25-29 July 2010

[12] Kundur P, Paserba J, Ajjarapu V et al (2004) Definition and classification of power system stability. IEEE Trans Power Syst 19(3):1387-1401

[13] Ejebe GC, Jing C, Waight JG et al (1998) Online dynamic security assessment in an EMS. IEEE Comput Appl Power 11(1):43-47

[14] Clark K, Miller NW, Walling R (2009) Modeling of GE solar photovoltaic plants for grid studies, version 1. GE International Inc., Schenectady

[15] Bergen AR (2000) Power system analysis. Prentice-Hall, Englewood Cliffs

[16] Kundur P (1994) Power system stability and control. McGraw Hill, New York

[17] Jing C, Vittal V, Ejebe GC et al (1995) Incorporation of HVDC and SVC models in the Northern State Power Co (NSP) for online implementation of direct transient stability assessment. IEEE Trans Power Syst 10(2):898-906

\section{Author Biographies}

Chaoyang JING is the Principal Engineer of eMIT, LLC in California, USA. He received his BS (1984) and MS (1987) in Electrical Engineering from Tsinghua University, and Ph.D. (1990) in Electrical Engineering from Zhejiang University. He had served in Iowa State University and Cornell University as a postdoctoral fellow from 1992 until 1994. His research interests include power system dynamics, Common Information Model (CIM), IT technology applications to power systems, renewable energy integration, database application, web application, and Service Oriented Architecture (SOA) in a variety of industries. He is also an adjunct Professor at California State Polytechnic University.

Baiqing LI is the director of Power System Research Division of China Electric Power Research Institute (CEPRI) in Beijing, China. He received his BS (1984) in Electrical Engineering from Tsinghua University, and MS (1987) in Electrical Engineering from CEPRI. 